\title{
New device to support patients with acute respiratory distress: high flow, nebulization and oxygen therapy with automated Fi02 titration
}

\author{
F Lellouche ${ }^{1 *}$, E L'Her $^{2}$, P-A Bouchard ${ }^{3}$, M Delorme ${ }^{4}$, T Elfaramawy ${ }^{5}$, B Gosselin ${ }^{5}$ \\ From ESICM LIVES 2015 \\ Berlin, Germany. 3-7 October 2015
}

\section{Introduction}

Hyperoxia induced hypercapnia has been described more than 60 years ago [1] and first recommendations to avoid hyperoxia in COPD patients were provided more than 50 years ago [2]. Alarm bell was recently raised [3] after the demonstration that high oxygen flows could increase mortality in patients with respiratory distress [4].

\section{Objectives}

To develop a device continuously adjusting Fi02 with high flows of air/oxygen based on the Free02 system that titrates oxygen flow delivered to patients with the aim to maintain a constant oxygenation [5].

\section{Methods}

The Free02 system was modified to allow a mixture of oxygen and air administration with a constant gas flow. The proportion of oxygen is based on an advanced closed loop to maintain a constant Sp02. We compare this new prototype with Optiflow set with minimal Fi02 (35\%). Both devices are set at $30 \mathrm{~L} / \mathrm{min}$, and we plan to recruit 10 healthy subjects'. The experimental conditions are the following: healthy subjects will initially breath room air ( 5 minutes), followed by 5 minutes of induced hypoxemia (nitrogen administration), and return to initial conditions (breathing room air for 5 minutes). We record Sp02, respiratory rate, heart rate and Fi02 delivered.

\section{Results}

We will present results of this comparison in 10 healthy subjects. Initial data demonstrate the feasibility to deliver variable oxygen flows administered with air at high flows (from 20 to $60 \mathrm{~L} / \mathrm{min}$ ). In this study, the flow is maintained constant at $30 \mathrm{~L} / \mathrm{min}$. During nitrogen administration to the healthy subjects, with the new prototype controlling oxygen/air administration, the oxygen increases (leading to a Fi02 increase) to maintain constant the Sp02 level (set at $94 \%$ in this study), and the air flow decreases to maintain constant the total flow $(30 \mathrm{~L} / \mathrm{min})$. After cessation of nitrogen, the oxygen flow (and Fi02) are automatically reduced (Figure). In the first included subjects, with Optiflow. hyperoxia is present during the first and third condition (breathing room air) and hypoxemia occur during nitrogen administration.

\section{Conclusions}

This new device may help to optimize oxygenation avoiding hypoxemia and hyperoxia during high flow oxygen therapy.

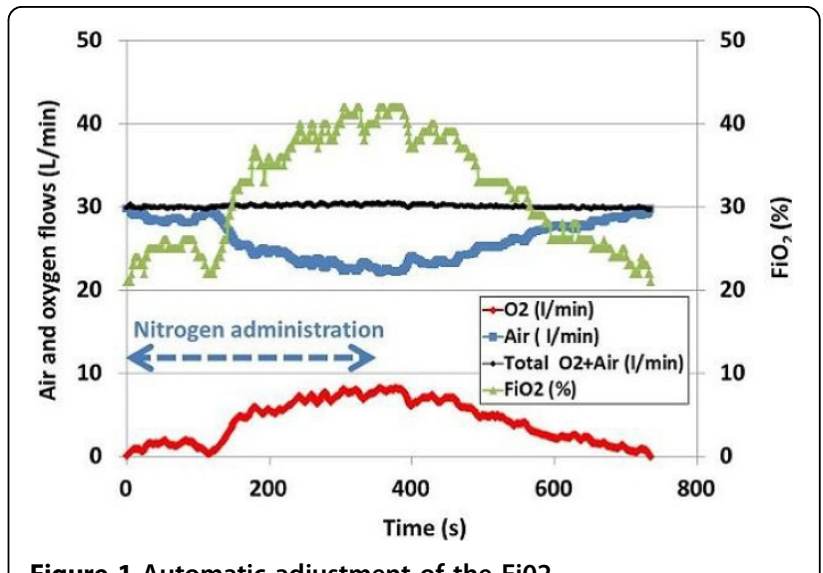

Figure 1 Automatic adjustment of the Fi02.

${ }^{1}$ Institut Universitaire de Cardiologie et de Pneumologie de Québec, Lac-

Beauport, Canada

Full list of author information is available at the end of the article

(c) 2015 Lellouche et al.; This is an Open Access article distributed under the terms of the Creative Commons Attribution License (http://creativecommons.org/licenses/by/4.0), which permits unrestricted use, distribution, and reproduction in any medium, provided the original work is properly cited. 


\section{Grant Acknowledgement}

Fond de recherche en Santé du Québec, Canadian Fundation for Innovation

\section{Authors' details}

'Institut Universitaire de Cardiologie et de Pneumologie de Québec, LacBeauport, Canada. ${ }^{2} \mathrm{CHRU}$ Brest, Brest, France. ${ }^{3}$ Institut Universitaire de Cardiologie et de Pneumologie de Québec, Québec, Canada. ${ }^{4} \mathrm{CHU}$ Bordeaux, Bordeaux, France. ${ }^{5}$ Université Laval, Département de Génie Électrique et Informatique, Québec, Canada.

Published: 1 October 2015

\section{References}

1. Davies CE, Mackinnon J: Neurological effects of oxygen in chronic cor pulmonale. Lancet 1949.

2. Campbell EJ: A method of controlled oxygen administration which reduces the risk of carbon-dioxide retention. Lancet 1960.

3. Beasley R, et al: High-concentration oxygen therapy in COPD. Lancet 2011.

4. Austin MA, et al: Effect of high flow oxygen on mortality in chronic obstructive pulmonary disease patients in prehospital setting: randomised controlled trial. BMJ 2010.

5. Lellouche F, L'her E: Automated oxygen flow titration to maintain constant oxygenation. Respir Care 2012.

doi:10.1186/2197-425X-3-S1-A276

Cite this article as: Lellouche et al:: New device to support patients with acute respiratory distress: high flow, nebulization and oxygen therapy with automated Fi02 titration. Intensive Care Medicine Experimental 2015 3(Suppl 1):A276.

\section{Submit your manuscript to a SpringerOpen ${ }^{\circ}$ journal and benefit from:}

- Convenient online submission

- Rigorous peer review

- Immediate publication on acceptance

- Open access: articles freely available online

- High visibility within the field

- Retaining the copyright to your article 